Preconception care for infertile couples: Nurses' and midwives' roles in promoting better maternal and birth outcomes.

\author{
Allan, HT \\ http://hdl.handle.net/10026.1/12163
}

10.1111/jocn.14586

Journal of Clinical Nursing

Wiley

All content in PEARL is protected by copyright law. Author manuscripts are made available in accordance with publisher policies. Please cite only the published version using the details provided on the item record or document. In the absence of an open licence (e.g. Creative Commons), permissions for further reuse of content should be sought from the publisher or author. 


\title{
Preconception care for infertile couples: Nurses' and midwives' roles in promoting better maternal and birth outcomes
}

\author{
Helen T Allan ${ }^{1}$ (D) | Ginny Mounce ${ }^{2}$ | Esther Crespo ${ }^{3}$ | Jill Shawe
}

${ }^{1}$ Middlesex University, London, UK

${ }^{2}$ University of Oxford/Oxford Fertility, Oxford, UK

${ }^{3}$ University of Barcelona, Barcelona, Spain

${ }^{4}$ University of Plymouth, Plymouth, UK

\section{Correspondence}

Helen T. Allan, Middlesex University, WG14 The Burroughs, Hendon, London NW4 4BT, UK.

Email: h.allan@mdx.ac.uk

Funding information Hospital Clinic de Barcelona, Maternitat, Spain, funded a travel scholarship to the UK. Middlesex University generously provided support for the visiting scholar.
Introduction: Preconception care promotes better maternal outcomes, may assist in preventing birth defects and improves fertility awareness among healthy childbearing couples. Yet, the significance of preconception care for infertile couples is undeveloped area of practice in Europe.

Aims and objectives: To discuss the importance of nurses and midwives in providing preconception care to infertile couples in the United Kingdom and Spain.

Design: Discursive paper.

Method: A comparison of different midwifery and nursing approaches to preconception care for infertile couples in two European countries.

Findings: At present, infertile couples' needs for preconception care are not routinely identified or understood. There is an opportunity for these needs to be considered and identified by nurses at the time of investigation for infertility or when planning pregnancy with assisted conception.

Conclusions: We argue that, by providing preconception care, nurses and midwives have an opportunity to deliver important advice to infertile couples in both primary care and specialist infertility services.

KEYWORDS

infertility, midwifery, nursing, preconception

\section{1 | INTRODUCTION}

\section{1 | Overview}

Preconception care promotes better maternal outcomes, may assist in preventing birth defects and improves fertility awareness among healthy childbearing couples (Atrash, Jack, \& Johnson, 2008; Atrash, Johnson, Adams, Cordero, \& Howse, 2006; Hemsing, Greaves, \& Poole, 2017; Poels, van Stel, Franx, \& Koster, 2017; Temel, van Voorst, Jack, Denktas, \& Steegers, 2014). It is beginning to be recognised that preconception care is also important for infertile couples in both primary care and fertility clinics (Homan, Davies, \& Norman, 2007; Kelly-Weeder \& O'Connor, 2006; Vause, Jones, Evans, Wilkie, \& Leader, 2009) as well as interconception care between pregnancies (Hemsing et al., 2017).
Countries differ in the availability and delivery of preconception services (Backhausen et al., 2014), and consequently, Shawe et al. (2015) have argued for the development of standard European guidelines.

Preconception care is:
the provision of biomedical, behavioural and social health interventions to women and couples before con- ception occurs in order to improve pregnancy outcomes, women's health and the health of future generations. (Posner, Johnson, Parker, Atrash, \& Biermann, 2006; s198; World Health Organisation [WHO] 2013a, p. 1)

There are national- and population-based systems to monitor maternal behaviours, conditions and experiences that occur before, during and after pregnancy (NIHR Dissemination Centre, 2017; Robbins et al., 2014), but it is estimated that essential preconception 
health interventions will be provided too late in $40 \%$ of all pregnancies (WHO, 2013b). Unhelpfully, all preconception guidance presumes women schedule pregnancies when many pregnancies are unplanned (Fabre et al., 2014; Oza-Frank, Kachoria, Keim, \& Klebanoff, 2015).

Preconception care given at the right time is known to improve a range of health outcomes (Association of Maternal and Child Programs, 2007) during pregnancy and childbirth. These include lower maternal and child mortality and fewer complications in pregnancy (WHO, 2013a,b). The review "Better Beginnings. Improving health for Pregnancy" (NIHR Dissemination Centre, 2017) suggests healthcare professionals have opportunities to improve maternal health when women access health services unconnected with pregnancy. However, as the antenatal period is generally when contact is first made by women, opportunities for optimal preconception interventions may be missed (Goossens et al., 2016; Nekuei, Esfahani, \& Kazemi, 2012). A UK survey suggested that, on average, contact with a healthcare professional is first made at 8 weeks of gestation (Redshaw \& Henderson, 2015). Eight weeks of gestation is too late for lifestyle changes to improve pregnancy outcomes as critical foetal organ development occurs before this, when a lot of women may not realise they are pregnant (Goossens et al., 2016; Tydén, 2016).

Europe is seeing delayed childbearing, increasing obesity, gestational and pregestational diabetes and smoking among women (Bortolus et al., 2017). These all contribute to poorer outcomes for pregnancy and negatively effect women's reproductive health. Preconception assessment presents an opportunity for identifying women with or at risk of these morbidities (Hemsing et al., 2017). However, current policies and guidance for preconception care for otherwise healthy couples are fragmented if not inconsistent (Bortolus et al., 2017; Shawe et al. 2015) with little evidence of (a) why preconception care is not a priority for women and (b) why healthcare professionals do not routinely deliver preconception care (Goossens et al., 2016; Tuomainen, Cross-Bardell, Bhoday, Qureshi, \& Kai, 2013).

Preconception care may include the delivery of a number of preventative and interactive programmes (Bortolus et al., 2017), including advice on lifestyle, to optimise pregnancy outcomes on issues such as folic acid, genetic screening, environmental health, interpersonal violence, planned pregnancies, sexually transmitted infections, mental health, drug and alcohol use, vaccination programmes, female genital mutilation (FGM) and infertility/subfertility. This advice is important at a societal and individual level and can be empowering, particularly for women (Katz Rothman, 2014). Delivering preconception care may therefore produce the holistic, woman-centred care (Royal College of Midwives, 2014) that nurses wish to provide.

\section{2 | Infertility and preconception care}

Infertility is present when a couple does not become clinically pregnant after a year or more of regular unprotected sexual intercourse. The WHO (2016) sees it as a serious disability in the childbearing population (WHO, 2016); 48.5 million couples are estimated to be infertile worldwide (Mascarenhas, Flaxman, Boerma, Vanderpoel, \& Stevens, 2012).

\section{What does this paper contribute to the wider global clinical community?}

- This study builds on existing literature on preconception care for fertile couples, those who conceive spontaneously.

- We address the gap in nursing and midwifery practice internationally in preconception care for infertile couples.

- We suggest a framework for nursing and midwifery-led preconception care for infertile couples.

Physiological, genetic, environmental and social factors contribute to a couple's infertility and to the inability to deliver a healthy infant. In the UK and Spain, the incidence of infertility has risen with one in seven heterosexual couples affected (NICE, 2013). In 30\% of referred cases for infertility investigations, two or more causes of infertility coexist which make diagnosis and treatment challenging. After diagnostic testing, $15 \%-30 \%$ of couples are diagnosed with unexplained infertility (NICE, 2013).

Biologically, women are most fertile between ages 18 and 30 years and the ability to conceive and bear children declines progressively (Balasch \& Gratacos, 2011). However, the reproductive behaviour in most Europeans countries has shifted to later childbearing (Kocourkova, Burcin, \& Kucera, 2014). Births are more strictly planned, with greater numbers of women delaying conception until age 40 or over (Fulford, Bunting, Tsibulsky, \& Boivin, 2013) and choosing to have fewer children (Mascarenhas et al., 2012). Older age at conception affects fertility, but seemingly, the need for preconception advice and care in this respect may go unrecognised by health professionals and couples themselves (Crespo Mirasol, 2015).

If planning to have a child is delayed, seeking advice about preconception care may also be delayed. This is important given that preconception care can raise awareness of the menstrual cycle and the optimum times for conception. In addition, awareness of agerelated fertility and infertility is low. Habbema, Eijkemans, Leridon, and te Velde (2015) have shown how young people overestimate the effectiveness of fertility treatments such as in vitro fertilisation (IVF), believing they can conceive spontaneously and easily after 35 years of age. The optimum age for conceiving spontaneously is 32 years old or younger for a single child, at 27 years for two and at 23 years for three children. While it is the choice of each individual and couple to determine whether they intend to have a child, and if so the size of their family unit and the timing, the authors suggest that this knowledge is important for couples to plan their family. Habbema et al. (2015) recommend preconception care to increase public awareness of age-related fertility. According to Kocourkova et al. (2014), delayed birth timing is key to understanding the increased demand and provision of assisted reproductive techniques (ART). Chodorow (2003) argues delayed childbearing is socially reproduced both through couples' ambivalence over parenthood but also by the 
availability of ARTs. She argues that women are disconnected from their biological, reproductive age by social factors such as work. They are encouraged in this by changing social pressures for women to be independent. ARTs may suggest to young women and the public that childbearing can be delayed. But little evidence that health professional curricula are changing to challenge these perceptions or to motivate health professionals to support young women in their reproductive choices (Nekuei, Kazemi, \& Hasanzadeh, 2014; Nekuei et al., 2012).

Preconception care for infertile couples, also through raising awareness of these issues and providing interventions, may enhance chances of conception and pregnancy; however, neither the awareness nor interventions can be introduced if this service is not sought in the first place (Chodorow, 2003; Joelsson et al., 2016). The number of infertile couples seeking a referral for infertility varies enormously worldwide (Boivin, Bunting, Collins, \& Nygren, 2007). A referral for fertility advice includes initial consultation with a primary care practitioner for difficulties in conceiving to attendance at a specialist fertility clinic. There is also wide variation in the provision and funding of fertility services (Boivin et al., 2007). In developed countries, despite the demand being around $42 \%$, less than $25 \%$ receive any specialist infertility treatment (Boivin et al., 2007). In nations like the UK, only $56 \%$ of couples seek help from a doctor when they have problems conceiving, with $20 \%$ delaying this for over two years. Fulford et al. (2013) argue that in general couples are not well informed about fertility issues, and this can contribute to delay in identifying infertility risk factors and then seeking medical help.

According to the International Standards of Infertility Practice (2015, p.2):

Women and their partners who seek advice and help to conceive should be provided with information and support to optimise their health and environmental circumstances in order to improve their reproductive potential and the outcome for both mother and baby.

As discussed, the most critical period for foetal organ development is between three to eight weeks, (Tydén, 2016). As infertile couples are intensively monitored and in contact with a range of health professionals while attending infertility clinics, they are well placed to optimise their prepregnancy health (Anderson, Norman, \& Middleton, 2010). There may be a gap in preconception care between healthcare professionals in general practice who may have a poorer understanding of infertility and fertility specialists who may be focused on the infertility and not on preconception advice (Mounce, 2017).

\section{2 | AIMS}

We discuss the role of midwives and nurses in providing preconception care to infertile couples by comparing nursing and midwifery-led preconception services in the UK and Spain.

\section{METHODS}

This position paper was written after a study trip to the United Kingdom (UK) from Spain by one of the authors. We compare nursing and midwifery-led preconception services in the UK and Spain to add to the emerging international literature on preconception care for infertile couples. All four authors are nurses and/or midwives who have researched preconception care (Stephenson et al., 2014) or infertility (Allan, Payne, \& De Lacey, 2009; Crespo Mirasol, 2015; Mounce, 2017). We have all noted the lack of preconception care for infertile couples (Allan \& Finnerty, 2007; Allan \& Mounce, 2015; Crespo Mirasol, 2015; Mounce, 2017) and, with others (Goossens et al., 2016), the lack of attention to this area of practice in curricula and professional practice guidelines. Methods included (a) a literature review to identify papers relating to the role of nurses and midwives in providing preconception and interconception care for fertile and infertile couples. The review was conducted using the databases MEDLINE, CINAHL and Cochrane Library, using the Boolean operators AND and OR, databases reviewing studies with an unlimited publication date, English and Spanish language. Key search terms were used: preconception care, interconception care, infertility, nursing and midwifery. The search was conducted in 2016 This review suggests that infertile couples do not access preconception care either in primary care or in specialist fertility clinics despite guidance (European Society of Human Reproduction and Embryology [ESRHE], 2015). (b) A comparison of Spanish and British nursing and midwifery-led preconception care which illustrates different models in the provision of preconception care for infertile couples. We argue that the benefits of preconception care to promote better maternal outcomes and to prevent birth defects in all couples are well known. Yet, the significance of preconception care for infertile couples is undeveloped area of nursing and midwifery practice in Europe.

\section{4 | FINDINGS}

\subsection{Preconception care in the UK and Spain}

Women with preexisting medical conditions are considered "high risk" for pregnancy and so may receive preconception advice as part of a multidisciplinary model of care (Bick et al., 2014). However, as discussed earlier, this often only happens once women are already pregnant, and as Shawe et al. (2015) argue, while preconception care for women with existing morbidities is accepted practice, the provision for healthy women is less consistent across Europe. Even in Spain where preconception care is available, only $10 \%$ of Spanish couples voluntarily access a preconception clinic even when planning pregnancy (Sociedad Española de Ginecología y Obstetricia [SEGO], 2010). Despite this, it is claimed that $70 \%$ of couples are interested in increasing their knowledge of pregnancy and optimal prepregnancy lifestyles (Vause et al., 2009). Fulford et al. (2013) found that, where women report an intention to take action to improve pregnancy outcome, this is based on their knowledge about fertility and their perceived or known risk of infertility. 
Preconception care in the UK is not provided routinely although women may seek advice from general practitioners, practice nurses and community midwives (Heyes, Long, \& Mathers, 2004). Thus, the delivery of preconception care is seen as part of the public health role in nursing and is included in the nursing and midwifery UK curricula (Nursing \& Midwifery Council [NMC], 2009; Bye et al., 2016), but whether such public health roles are effective and which professional group is ultimately responsible for preconception care remains unclear (Bye et al., 2016; Sanders, Hunter, \& Warren, 2016; Shawe et al., 2015).

In Spain, there is publically funded provision for preconception care; women can request an appointment for preconception advice with a midwife or attend preconception clinics in primary care. In Spain, it is expected that preconception should be individualised and delivered by all health professionals involved in providing reproductive care (SEGO, 2010).

In both countries, antenatal care and pregnancy guidelines promote the importance of good health before pregnancy for all women; campaigns, such as folic acid supplementation before conception, are supported nationally (Sociedad Española de Ginecología y Obstetricia., 2010; Shawe et al., 2015; National Institute for Health \& Care Excellence [NICE] 2017).

\subsection{Fertility services and preconception care}

A systematic review (Anderson et al., 2010) found no evidence that preconception care is offered routinely to infertile couples. Anderson et al. (2010) make the point that this gap in provision is important because infertile couples' chances of conceiving and becoming parents, affected by social factors such as lifestyle choices and delayed childbearing, could be improved if supported through preconception care. This gap is particularly significant for the many couples who delay or do not seek specialist advice for infertility, despite being seen in primary care by GPs, nurses or midwives for other reasons. Providing these couples with preconception care may go some way to filling this gap and improve both their chances of conception and healthy pregnancy.

There is evidence that some fertility clinics are introducing fertility enhancing lifestyle support (Klonoff-Cohen, 2005). Allan et al. (2009) argue that women are proactive in seeking pregnancy even if this means greater surveillance by health professionals including increased surveillance of their bodies (Gentile, 2013; Katz Rothman, 2014; Lupton, 2012). At the same time, there is growing evidence that infertile couples proactively and independently, that is, without health professional guidance or interference, manage their infertility and any attempts at achieving parenthood through using ARTs (Hawkins et al., 2014; Rossi et al., 2016). Infertile couples often also anticipate that ARTs may be unable to overcome their infertility and decide to take action themselves. They consult many sources for health advice, not only doctors, and alternative and lay help-seeking behaviours are common (Crespo Mirasol, 2015; Mounce, 2017).

The public perception of ART availability is also at odds with the financial reality in which many treatments are rationed (Allan et al.,
2009), and there is widespread variation in which services, such as ART treatments and preconception care, are covered internationally through medical insurance (International Federation of Fertility Societies (IFFS), 2013).

In the UK, couples would self-refer to their publically funded general practitioner in primary care where initial investigations would be undertaken. There is little reported nursing input at this stage. Unlike in Spain, it is rare for nurses or midwives to be involved in providing a service such as running preconception clinics at this point. After referral to specialist fertility clinics, there may be further opportunity for preconception care but no evidence that this is delivered (Kelly-Weeder \& O'Connor, 2006; Allan et al., 2009). Instead, Mounce (2017) found that the focus is immediately on the potential for ARTs. Mounce (2017) argues that couples resist this technological imperative by seeking self-help or complementary health advice.

In Spain, women and couples can self-refer or be referred to a gynaecologist in primary care by their GP for information regarding care and treatment options for sub/infertility. Spanish midwives, unlike in the UK, also provide care to women planning for pregnancy in the community; in other words, they may offer preconception care, although this practice varies across the country and is not evaluated (Crespo Mirasol, 2015). Midwives in Spain are obstetric and gynaecologist specialist nurses and register as a midwife after completing a nursing registration. Community midwives offer obstetric clinics (e.g., pregnancy care, antenatal classes, postpartum care, breastfeeding support but not home delivery) and gynaecological care (e.g., contraception care, sexually transmitted infections, preconceptual care and cervical cancer screening). These services are publically funded (Departament de Salut, 2016). Women who experience problems in conceiving are seen at the primary care clinic at the sexual and reproductive health unit either by a gynaecologist or a midwife. Couples are then referred together to the specialist gynaecologist in primary care where initial information regarding care and treatment options is provided. Couples who fail to conceive at this point are referred to specialist fertility services in tertiary care (Departament de Salut, 2016).

\section{5 | DISCUSSION}

For those couples who remain unable to conceive or continue pregnancies, conception may be delayed and referral to specialist teams may become necessary (Mounce, 2017; NICE, 2016). ARTs may be enhanced by self-help and lifestyle changes which a couple may make to increase their chances of conceiving prior to and during cycles of assisted conception (NICE, 2013). Preconception care may increase these agentic acts (Hemsing et al., 2017; Kelly-Weeder \& O'Connor, 2006). Mounce (2017) has shown that infertile couples resist the hegemony of ARTs by seeking preconception care themselves from complementary health practitioners.

We argue that more awareness of the potential of preconception care and its outcomes needs to be raised in both primary care and fertility clinics among healthcare professionals including nurses and 
midwives. Primary care and fertility clinic healthcare professionals can provide couples with preconception advice. Research shows that, despite guidance on referrals for infertile or subfertile couples (Departament de Salut, 2016; NICE, 2013), many couples experience a delayed referral and as a consequence do not receive either investigations of infertility or preconception advice sufficiently early enough (Anderson et al., 2010; Crespo Mirasol, 2015; Mounce, 2017).

ESHRE (2015) recommends assessment of the psychosocial needs of women and men before fertility treatment to enable a psychosocially healthy experience of their treatment. As Kelly-Weeder and O'Connor (2006) suggest chances of conception can be optimised by couples themselves with information and advice and encouragement. Many unhealthy behaviours and lifestyle choices that negatively affect general and reproductive health, as well as chances of treatment success, are amenable to change (KlonoffCohen, 2005). Preconception counselling can assist (Joelsson et al., 2016; ESHRE Psychology and Counselling Guideline Development Group, 2016) women and men in this endeavour.

While it is possible to change unhealthy lifestyle factors, to reduce or even eliminate them to help couples to conceive, adherence with these recommendations could be improved through greater awareness among health professionals in primary care and fertility clinics (Joelsson et al., 2016). However, how effective preconception interventions can best be delivered, and whether specific recommendations change behaviour (Anderson et al., 2010; Barret et al., 2015; Shawe et al. (2015)) and who should deliver preconception interventions (Hemsing et al., 2017; Kelly-Weeder \& O'Connor, 2006) are future research questions.

\section{6 | RELEVANCE FOR CLINICAL PRACTICE: NURSING, MIDWIFERY AND PRECONCEPTUAL CARE}

While European fertility guidance recommends that couples have access to preconception care (European Society Human \& Reproduction and Embryology, 2015), it is unclear who assumes responsibility for delivering this care. In the world of assisted reproduction, selfhelp strategies for couples are not promoted (Allan et al., 2009; Ockhuijsen, Gamel, van den Hoogen, \& Macklon, 2012). Such strategies as Ockhuijsen et al. (2012, p. 1157) suggest, "receive little attention in the often commercial race to push couples though IVF treatment before they have had the opportunity or support to optimize the physical and mental circumstances for a pregnancy to occur". Indeed, as Mounce (2017) argues, in the UK, the tenor of initial fertility clinic consultations is frequently focused on directing couples to IVF. Nevertheless, recent interest in the nursing role in preconception care for infertile couples is beginning to emerge slowly (Allan \& Mounce, 2015; Kelly-Weeder \& O'Connor, 2006).

In the UK, a major barrier to this is the model of service provision; contact with nurses or midwives is not routinely offered at an early or pregnancy planning stage, for example, in primary care. This differs from Spain where women/couples can request preconception care from midwives or GPs, although Crespo Mirasol (2015) shows that this advice is not routine. Spanish midwives assume responsibility for preconception care in primary health services as well as in maternal health (although this is not evaluated), whereas in the UK, midwives would not expect to deliver preconception care but neither would fertility clinic nurses (Allan, 2013; Nekuei et al., 2014; Ockhuijsen et al., 2012) or indeed primary health nurses (Allan \& Mounce, 2015). This UK experience reflects a general pattern in health systems across Europe in relation to preconception care (Anderson et al., 2010; Shawe et al., 2015; Van Heesch, de Weerd, Kotey, \& Steegers, 2006). In the Netherlands, for example, Van Heesch et al. (2006) suggest the vast majority of community midwives were willing to provide preconception care and over half felt it was their responsibility to do so; however, most (79\%) claimed to lack knowledge and time to deliver preconception care.

In the UK, it is possible that caseload midwifery model could allow some preconception care by midwives (Killingley, 2017) although inadequate awareness of infertility and fertility treatments among midwives (Mounce, 2009) might hamper its effectiveness. Midwives would not normally encounter couples outside pregnancy, and therefore, their role in providing care and advice to infertile couples would be unusual (Wilson \& Leese, 2013). Unfortunately, although the provision of women-centred care is a key issue in midwifery practice (NMC, 2009), the requirement for the midwife to provide preconception care has not been reiterated in the latest standards.

\section{7 | CONCLUSIONS}

We have argued that currently nursing and/or midwifery-led preconception care in Spain is not evaluated and in the UK is not routinely offered or utilised, despite there being a clear need for infertile couples. In the UK, this may be due to the gap between primary and infertility care provision, especially where couples delay childbearing and may subsequently require assistance to conceive. In Spain, preconception care is more widely available, but uptake is low and not routine. The lack of preconception care for infertile couples may be a reflection of a lack of continuity in women's health reported elsewhere (Royal College of Obstetricians and Gynaecologists, 2011).

We have argued that infertile couples' preconception needs are unrecognised, yet the opportunities for fertility awareness exist in both primary care and fertility clinics. We suggest patient-centred preconception care for infertile couples should encompass four components:

1. Risk assessment which may lead to further screening, investigations and referral to fertility/other specialists

2. Health promotion, including periconception folic acid supplement use and well-being advice to deal with the stress of infertility (Anderson et al., 2010). 
3. Lifestyle intervention and modification advice to change or eliminate risk factors such as smoking cessation and weight loss (Van der Steeg et al., 2008).

4. Counselling for family planning including age-related fertility awareness.

Preconception care should be actively offered by all healthcare professionals. Nurses in fertility clinics and GPs in primary care are ideally placed to open up a discussion about preconception care with infertile couples, promoting the agency of these patients during otherwise relatively powerless investigation and treatment stages. Infertile couples could be offered an initial fertility and preconception assessment prior to referral for specialist consultation to discuss medical options for conception. As the Spanish community midwife's role shows, there are also models for integrating preconception care for women and couples in the community. Education standards and curricula for both midwives and nurses should include preconception care for both the fertile women and her partner and the infertile couple.

\section{ACKNOWLEDGEMENTS}

The authors would like to thank Hospital Clinic de Barcelona, Maternitat, Spain, and Middlesex University.

\section{CONFLICT OF INTEREST}

None of the authors have any conflict of interests.

\section{CONTRIBUTION}

Study design: HA GM EC; data collection and analysis: HA GM EC; and manuscript preparation: HA GM EC JS.

\section{ORCID}

Helen T Allan (iD http://orcid.org/0000-0001-9391-0385

\section{REFERENCES}

Allan, H. T. (2013). The anxiety of infertility: The role of the nurses in the fertility clinic. Human Fertility, 16(1), 17-22. https://doi.org/10. 3109/14647273.2013.778423

Allan, H., \& Finnerty, G. (2007). The practice gap in the care of women following successful infertility treatments: Unasked questions in midwifery and nursing? Human Fertility, 10(2), 99-104. https://doi.org/ 10.1080/14647270601050320

Allan, H., \& Mounce, G. (2015). Managing infertility in primary care. Practice Nursing, 26(9), 440-443. https://doi.org/10.12968/pnur.2015.26. 9.440

Allan, H. T., Payne, D., \& De Lacey, S. (2009). The socio-cultural context of assisted reproductive technologies: The shaping of 'routine practices. Nursing Inquiry, 16, 241-250. https://doi.org/10.1111/j.14401800.2009.00461.x
Anderson, K., Norman, R. J., \& Middleton, P. (2010). Preconception lifestyle advice for people with subfertility. Cochrane Database of Systematic Reviews, (Issue 4), CD008189.

Association of Maternal and Child Programs (2007). Preconception health and health care. Retrieved from http://www.amchp.org/programsa ndtopics/womens-health/resources/documents/preconception-health. pdf

Atrash, H., Jack, B. W., \& Johnson, K. (2008). Preconception care: A 2008 update. Current Opinion in Obstetrics and Gynecology, 20(6), 581-589. https://doi.org/10.1097/GCO.0b013e328317a27c

Atrash, H. K., Johnson, K., Adams, M., Cordero, J. F., \& Howse, J. (2006). Preconception care for improving perinatal outcomes: The time to act. Maternal Child Health Journal, 10, S3-S11. https://doi.org/10. 1007/s10995-006-0100-4

Backhausen, M. G., Ekstrand, M., Tydén, T., Magnussen, B. K., Shawe, J., Stern, J., \& Hegaard, H. K. (2014). Pregnancy planning and lifestyle prior to conception and during early pregnancy among Danish women. European Journal of Contraception and Reproductive Health Care, 19, 57-65. https://doi.org/10.3109/13625187.2013.851183

Balasch, A., \& Gratacos, V. (2011). Delayed childbearing: Effects on fertility and the outcome of pregnancy. Fetal Diagnosis and Therapy, 29, 263-273. https://doi.org/10.1159/000323142

Barret, G., Shawe, J., Howden, B., Patel, D., Ojukwu, O., Pandya, P., \& Stephenson, J. (2015). Why do women invest in pre-pregnancy health and care? A qualitative investigation with women attending maternity services. BMC Pregnancy and Childbirth, 15, 236. https://doi.org/10. 1186/s12884-015-0672-3

Bick, D., Beake, S., Chappell, L., Ismail, K. M., McCance, D. R., Green, J., \& Taylor, C. (2014). Management of pregnant and postnatal women with pre-existing diabetes or cardiac disease using multi-disciplinary team models of care: A systematic review. BMC Pregnancy and Childbirth, 14, 428. https://doi.org/10.1186/s12884-014-0428-5

Boivin, J., Bunting, L., Collins, J. A., \& Nygren, G. N. (2007). International estimates of infertility prevalence and treatment-seeking: Potential need and demand for infertility medical care. Human Reproduction, 22 (6), 1506-1512. https://doi.org/10.1093/humrep/dem046

Bortolus, R., Oprandi, N. C., Morassutti, F. R., Marchetto, L., Filippini, F., Agricola, E., ... Mastroiacovo, P. (2017). Why women do not ask for information on pre-conception health? A qualitative study. BMC Pregnancy and Childbirth, 17(5), 1-11.

Bye, A., Shawe, J., Stephenson, J., Bick, D., Brima, N., \& Micali, N. (2016). Differences in pre-conception and pregnancy healthy lifestyle advice by maternal BMI: Findings from a cross sectional survey. Midwifery, 42, 38-45. https://doi.org/10.1016/j.midw.2016.09.013

Chodorow, N. J. (2003). Too late: Ambivalence about motherhood, choice and time. In M. A. Alizade (Ed.), Studies on femininity (pp. 27-40). London, UK: Karnac Books.

Crespo Mirasol, E. (2015). Percepciones de las mujeres, parejas y profesionales durante el embarazo, parto y postparto tras someterese a técnicas de reproducción asistida ( $\mathrm{PhD}$ thesis). (Perceptions of women, family and professionals during and after assisted conception). University of Barcelona, Spain. Retrieved from: http://hdl.handle.net/10803/ 351715

Departament de Salut (2016). Protocol de les tècniques de reproducció humana assistida (Protocols for assisted human conception technologies). Retrieved from: http://canalsalut.gencat.cat/web/.content/home_ca nal_salut/ciutadania/la_salut_de_la_a_a_la_z/r/reproduccio_assistida/d ocuments/protocol_rha_def.pdf

European Society Human \& Reproduction and Embryology (2015). Psychosocial care in infertility and medically assisted reproduction $-A$ guide for fertility staff. Retrieved from: http://www.eshre.eu/ /media/Files/ Guidelines/Psychology/ESHRE psychology guideline_2015_final_version 1_2.pdf

Fabre, E., Bermejo, R., Doval, J. L., Pérez-Campos, E., Martínez-Salmeán, J., \& Lete, I. (2014). Estudio observacional, transversal, de 
una muestra representativa de las mujeres españolas en edad fértil, sobre los cuidados, hábitos y promoción de la salud previamente y durante el embarazo: Estudio GESTMUJER. Progresos de Obstetricia y Ginecología, 57(7), 285-290. https://doi.org/10.1016/j.pog.2014. 05.004

Fulford, B., Bunting, L., Tsibulsky, I., \& Boivin, J. (2013). The role of knowledge and perceived susceptibility in intentions to optimize fertility: Findings from the International Fertility Decision- Making Study (IFDMS). Human Reproduction, 28(12), 3253-3262. https://doi.org/ 10.1093/humrep/det373

Gentile, K. (2013). Biopolitics, trauma and the public fetus: An analysis of preconception care. Subjectivity, 6(2), 153-172. https://doi.org/10. 1057/sub.2013.2

Goossens, J., Delbeare, I., Dhaenens, C., Willems, L., Van Hecke, A., Verhaege, S., \& Beeckman, D. (2016). Preconception-related needs of reproductive-aged women. Midwifery, 33, 64-72. https://doi.org/10. 1016/j.midw.2015.10.012

Habbema, J. D. F., Eijkemans, M. J. C., Leridon, H., \& te Velde, E. R. (2015). Realizing a desired family size: When should couples start? Human Reproduction, 30(9), 2215-2221. https://doi.org/10.1093/hum $\mathrm{rep} / \mathrm{dev} 148$

Hawkins, L. K., Rossi, B. V., Correia, K. F., Lipskind, S. T., Hornstein, M. D., \& Missmer, S. A. (2014). Perceptions among infertile couples of lifestyle behaviors and in vitro fertilization (IVF) success. Journal Assisted Reproduction and Genetics, 31(3), 255-260. https://doi.org/ 10.1007/s10815-014-0176-5

Hemsing, N., Greaves, L., \& Poole, N. (2017). Preconception health care interventions: A scoping review. Sexual \& Reproductive Healthcare, 14, 24-32. https://doi.org/10.1016/j.srhc.2017.08.004

Heyes, T., Long, S., \& Mathers, N. (2004). Preconception care: Practice and beliefs of primary care workers. Family Practice, 21(1), 22-27. https://doi.org/10.1093/fampra/cmh106

Homan, G. F., Davies, M., \& Norman, R. (2007). The impact of lifestyle factors on reproductive performance in the general population and those undergoing fertility treatment: A review. Human Reproduction, 13, 209-223.

International Federation of Fertility Societies (IFFS) (2013). IFFS surveillance. Retrieved from: https://c.ymcdn.com/sites/iffs.site-ym.com/re source/resmgr/iffs_surveillance_09-19-13.pdf

International Standards of Infertility Practice (2015). Standard 1. Pre-pregnancy advice and assessment. Recommendation for Practice. 1-6

Joelsson, L. S., Berglund, A., Wanggren, K., Lood, M., Rosenblad, A., \& Tydén, T. (2016). Do subfertile women adjust their habits when trying to conceive? Upsala Journal of Medical Sciences, 121(3), 184-191. https://doi.org/10.1080/03009734.2016.1176094

Katz Rothman, B. (2014). Editorial. Pregnancy, birth and risk: An introduction. Health, Risk \& Society, 16, 1-6. https://doi.org/10.1080/ 13698575.2013.876191

Kelly-Weeder, S., \& O'Connor, A. (2006). Modifiable risk factors for impaired fertility in women: What nurse practitioners need to know. Journal of the American Academy of Nurse Practitioners, 18, 268-276. https://doi.org/10.1111/j.1745-7599.2006.00130.x

Killingley, J. (2017). Personal communication. November 2017.

Klonoff-Cohen, H. (2005). Female and male lifestyle habits and IVF: What is known and unknown. Human Reproduction Update, 11(2), 179-203. Epub 2005 Feb 11.

Kocourkova, J., Burcin, B., \& Kucera, T. (2014). Demographic relevancy of increased use of assisted reproduction in European countries. Reproductive Health, 11(37), 1-10.

Lupton, D. (2012). Precious cargo: Foetal subjects, risk and reproductive citizenship. Critical Public Health, 22(3), 329-340. https://doi.org/10. 1080/09581596.2012.657612

Mascarenhas, M. N., Flaxman, S. R., Boerma, T., Vanderpoel, S., \& Stevens, G. A. (2012). National, regional, and global trends in infertility prevalence since 1990: A systematic analysis of 277 health surveys. PLOS Medicine, 9(12), e1001356. https://doi.org/10.1371/ journal.pmed.1001356

Mounce, G. (2009). Assisted reproduction: what do midwives need to know? RCM Midwives magazine. Feb/March 2009. Retrieved from: https:// www.rcm.org.uk/learning-and-career/learning-and-research/in-depthpapers/assisted-reproduction-what-do-midwives

Mounce, G. (2017). Experiences of the early 'infertility journey': An ethnography of couples commencing infertility investigations and treatment, Unpublished PhD thesis. University of Surrey, Guildford UK

Nekuei, N., Esfahani, M. H. N., \& Kazemi, A. (2012). Preconception counseling in couples undergoing fertility treatment. International Journal of Fertility \& Sterility, 6(2), 79-86.

Nekuei, N., Kazemi, A., \& Hasanzadeh, A. (2014). Preconception interventions in infertile couples. Journal Education Health Promotion, 3, 101. https://doi.org/10.4103/2277-9531.139683. eCollection

NICE (2013). Fertility problems: assessment and treatment. Clinical guideline. Retrieved from https://www.nice.org.uk/guidance/cg156

NICE (2016). Fertility overview. Retrieved from http://pathways.nice.org. uk/pathways/fertility

NICE (2017). Pre-conception - Advice and management. Retrieved from: https://cks.nice.org.uk/pre-conception-advice-and-management

NIHR Dissemination Centre (2017). Better beginnings. Improving Health for Pregnancy. Retrieved from: https://www.dc.nihr.ac.uk/themed-re views/Better-beginnings-web-interactive.pdf

NMC (2009). Standards for pre-registration midwifery education. Retrieved from: https://www.nmc.org.uk/globalassets/sitedocuments/standard s/nmc-standards-for-preregistration-midwifery-education.pdf

Ockhuijsen, H. D. L., Gamel, C. J., van den Hoogen, A., \& Macklon, N. S. (2012). Integrating preconceptional care into an IVF programme. Journal of Advanced Nursing, 68(5), 1156-1165. https://doi.org/10.1111/j. 1365-2648.2011.05829.x

Oza-Frank, R., Kachoria, R., Keim, S. A., \& Klebanoff, M. A. (2015). Provision of specific preconception care messages and associated maternal health behaviours before and during pregnancy. American Journal of Obstetrics and Gynecology, 212(3), 372.e1-8.

Poels, M., van Stel, H. F., Franx, A., \& Koster, M. P. H. (2017). Actively preparing for pregnancy is associated with healthier lifestyle of women during the preconception period. Midwifery, 50, 228-234. https://doi.org/10.1016/j.midw.2017.04.015

Posner, S. F., Johnson, K., Parker, C., Atrash, H., \& Biermann, J. (2006). The national summit on preconception care: A summary of concepts and recommendations. Maternal Child Health Journal, 10(5 Suppl), S197-S205.

Redshaw, M., \& Henderson, J. (2015). Safety delivered: A national survey of women's experience of maternity care. Oxford, UK: National Perinatal Epidemiology Unit, University of Oxford.

Robbins, C. L., Zapata, L. B., Farr, S. L., Kroelinger, C. D., Morrow, B., Ahluwalia, I., ... Barfield, W. D. (2014). Core state pre-conception health indicators. Pregnancy risk assessment monitoring system and behavioural risk factor surveillance system. MMWR, 63(3), 1-63.

Rossi, B. V., Bressler, L. H., Correia, K. F., Lipskind, S., Hornstein, M. D., \& Missmer, S. A. (2016). Lifestyle and in vitro fertilization: What do patients believe? Fertility Research and Practice, 12(2), 11. https://doi. org/10.1186/s40738-016-0026-5. eCollection

Royal College of Midwives (2014). High quality midwifery care. RCM report. Retrieved from https://www.rcm.org.uk/sites/default/files/ High\%20Quality\%20Midwifery\%20Care\%20Final.pdf

Royal College of Obstetricians and Gynaecologists (2011). High quality women's health care: A proposal for change. Expert Advisory Group Report. London, UK: RCOG Press. Retrieved from https://www.rcog. org.uk/globalassets/documents/guidelines/highqualitywomenshealth careproposalforchange.pdf 
Sanders, L., Hunter, B., \& Warren, L. (2016). A wall of information? Exploring the public health component of midwifery in England. Midwifery, 34, 253-260. https://doi.org/10.1016/j.midw.2015.10.013

Shawe, J., Delbaere, I., Ekstrand, M., Hegaard, H. K., Larsson, M., Mastroiacovo, P., ... Tydén, T. (2015). Preconception care policy, guidelines, recommendations and services across six European countries: Belgium (Flanders), Denmark, Italy, the Netherlands, Sweden and the United Kingdom. The European Journal of Contraception \& Reproductive Health Care, 20, 77-87. https://doi.org/10.3109/13625187.2014.990088

Sociedad Española de Ginecología y Obstetricia. (2010). Consulta preconcepcinonal. Protocolos Asistenciales en Obstetricia, 24(4), 272-280.

Stephenson, J., Patel, D., Barrett, G., Howden, B., Copas, A., Ojukwu, O., ... Shawe, J. (2014). How do women prepare for pregnancy? Preconception experiences of women attending antenatal services and views of health professionals. PLoS ONE, 9(7), e103085. https://doi. org/10.1371/journal.pone.0103085

Temel, S., van Voorst, S. F., Jack, B. W., Denktas, S., \& Steegers, E. A. P. (2014). Evidence-based preconceptual lifestyle interventions. Epidemiological Reviews, 36, 19-30. https://doi.org/10.1093/epirev/mxt003

Tuomainen, H., Cross-Bardell, L., Bhoday, M., Qureshi, N., \& Kai, J. (2013). Opportunities and challenges for enhancing preconception health in primary care: Qualitative study with women from ethnically diverse communities. British Medical Journal Open, 3(7), e002977. https://doi.org/10.1136/bmjopen-2013-002977

Tydén, T. (2016). Why is preconception health and care important? Upsala Journal of Medical Sciences, 121, 207. https://doi.org/10. 1080/03009734.2026.1211776

Van der Steeg, J. W., Steures, P., Eijkermans, M. J. C., Habbema, J. D. F., Hompes, P. G., Burggraaff, J. M., ... Mol, B. W. (2008). Obesity affects spontaneous pregnancy chances in sub-fertile, ovulatory women. Human Reproduction, 23, 324-328.

Van Heesch, P. N. A. C. M., de Weerd, S., Kotey, S., \& Steegers, E. A. P. (2006). Dutch community midwives' views on pre-conception care. Midwifery, 22(2), 120-124. https://doi.org/doi: 10.1016/j.midw.2005. 06.003
Vause, T., Jones, L., Evans, M., Wilkie, V., \& Leader, A. (2009). Pre-conception health awareness in infertility patients. Journal of Obstetrics and Gynaecology Canada, 31(8), 717-720. https://doi.org/10.1016/ S1701-2163(16)34275-X

Wilson, C., \& Leese, B. (2013). Do nurses and midwives have a role in promoting the well-being of patients during their fertility journey? A review of the literature. Human Fertility, 16(1), 2-9. https://doi.org/ 10.3109/14647273.2013.781687

World Health Organization (2013a). Meeting to develop a global consensus on preconception care to reduce maternal and childhood mortality and morbidity World Health Organization Headquarters, Geneva 6-7 February 2012 Meeting report. World Health Organisation, Geneva Switzerland. Retrieved from http://apps.who.int/iris/bitstream/10665/ 78067/1/9789241505000_eng.pdf

World Health Organization (2013b). Preconception care: Maximizing the gains for maternal and child health. Policy brief. World Health Organisation, Geneva Switzerland. Retrieved from https://www.who. int/maternal_child_adolescent/documents/preconception_care_polic y_brief.pdf

World Health Organization (2016). Sexual and reproductive health infertility definitions and terminology. World Health Organisation, Geneva Switzerland. Retrieved from www.who.int/reproductivehealth/topics/ infertility/definitions/en/

How to cite this article: Allan HT, Mounce G, Crespo E, Shawe J. Preconception care for infertile couples: Nurses' and midwives' roles in promoting better maternal and birth outcomes. J Clin Nurs. 2018;00:1-8. https://doi.org/10.1111/ jocn.14586 